\title{
Laparoscopic total gastrectomy for upper-middle advanced gastric cancer: analysis based on lymph node noncompliance
}

\author{
Qi-Yue Chen ${ }^{1,2,3}$. Guang-Tan Lin ${ }^{1,2}$. Qing Zhong ${ }^{1,2} \cdot$ Chao-Hui Zheng ${ }^{1,2,3} \cdot$ Ping $\mathrm{Li}^{1,2,3}$. Jian-Wei Xie ${ }^{1,2,3}$. \\ Jia-Bin Wang ${ }^{1,2,3}$. Jian-Xian Lin ${ }^{1,2,3}$. Jun Lu ${ }^{1,2,3} \cdot$ Long-Long Cao ${ }^{1,2}$. Chang-Ming Huang ${ }^{1,2,3}$ (D)
}

Received: 20 March 2019 / Accepted: 30 June 2019 / Published online: 12 July 2019

(c) The International Gastric Cancer Association and The Japanese Gastric Cancer Association 2019

\begin{abstract}
Background Increasing number of clinical studies have shown that laparoscopic distal gastrectomy (LDG) with D2 lymph node (LN) dissection is an effective method for the treatment of advanced gastric cancer (AGC). However, reports on the technical feasibility and oncology efficacy of laparoscopic total gastrectomy (LTG) in the treatment of AGC are rare.

Methods A retrospective analysis of the clinicopathologic data of 1313 patients with clinical stage of cT2-4aN0-3M0 undergoing laparoscopic radical gastrectomy with D2 LN dissection from June 2007 to December 2013 was performed. Noncompliance was defined as patients with more than one LN station absence as described in the protocol for D2 lymphadenectomy in the Japanese Gastric Cancer Association (JGCA). According to the literature, it was subdivided into LN compliance group (all LN stations were detected), minor LN noncompliance group (1-2 LN stations were not detected), major LN noncompliance group (more than $2 \mathrm{LN}$ stations were not detected). Based on the $\mathrm{LN}$ noncompliance, the surgical indications of LTG were analyzed with LDG as control.

Results Among the 1313 patients, 197 (39.20\%) patients and 321(39.71\%) patients in the LDG group and the LTG group had minor LN noncompliance, 59(11.70\%) patients and 163(20.10\%) patients had major LN noncompliance. The difference in the extent of LN noncompliance between the two groups was statistically significant $(p<0.001)$. COX proportional hazards regression analysis elucidated that the $\mathrm{LN}$ noncompliance was an independent prognostic factor for overall survival (OS). BMI $\geq 25 \mathrm{~kg} / \mathrm{m}^{2}$ and the history of previous abdominal surgery (PAS) were independent risk factors for major LN noncompliance in LTG group $(p<0.05)$, with which patients were defined as a LN noncompliance high-risk group. With the exception of LN noncompliance high-risk group, the difference in the extent of LN noncompliance between LTG group and LDG group was still statistically significant $(p=0.008)$. Tumor diameter $>60 \mathrm{~mm}$ is a preoperative risk factor for station \#5 LN noncompliance, and no preoperative risk factors for station \#6 LN noncompliance were found, with which patients were defined as LN noncompliance middle-risk group.

Conclusion LN noncompliance is an independent prognostic factor for poor prognosis in patients after LTG. Based on this finding, patients with BMI $\geq 25 \mathrm{~kg} / \mathrm{m}^{2}$, history of PAS and tumor diameter $>60 \mathrm{~mm}$ in the advanced stage of upper-middle gastric cancer represent high/middle-risk groups with LN noncompliance in LTG surgery, which should be carefully selected.
\end{abstract}

Keywords Gastric cancer · Laparoscopic total gastrectomy · D2 lymph node dissection · Lymph node noncompliance · Prognosis

Qi-Yue Chen and Guang-Tan Lin contributed equally to this work and should be considered co-first authors.

Electronic supplementary material The online version of this article (https://doi.org/10.1007/s10120-019-00986-0) contains supplementary material, which is available to authorized users.

Chang-Ming Huang

hcmlr2002@163.com

Extended author information available on the last page of the article

\section{Introduction}

Worldwide, gastric cancer (GC) is an important health problem, ranking fourth among the most common malignancies and second among the leading causes of cancer death [1]. Gastrectomy with adequate peri-peripheral LN dissection is the only possible way to cure GC, and it can improve the survival rate of patients [2-5]. Since Kitano 
first reported laparoscopic early gastric cancer (EGC) surgery, the development of laparoscopic instruments and the accumulation of surgeons' experience has led to the expansion of the use of laparoscopic surgery for EGC to its use for AGC [6-10]. Unlike EGC, adequate D2 LN dissection must be achieved in the surgical treatment of AGC, and an increasing number of clinical studies have shown that LDG with D2 LN dissection is an effective method for the treatment of AGC [5, 10-12]. CLASS01 by the Chinese Laparoscopic Gastrointestinal Surgical Society (CLASS) confirmed that the short-term and longterm outcomes of LDG in the treatment of AGC were not inferior to that of open distal gastrectomy [13, 14]. 3-year disease-free survival of patients assigned to the laparoscopic distal gastrectomy group was not inferior to that of patients assigned to the open distal gastrectomy group [14]. The COACT1001 trial from Korea confirmed the definite oncology efficacy of LDG for the treatment of AGC based on the LN noncompliance rate [15]. These studies suggest that the indication for LDG could be extended to locally AGC. Epidemiological studies have shown that the occurrence of upper-middle gastric cancer that currently requires total gastrectomy has increased in recent years [16]. At present, the comparative study of LTG and open total gastrectomy (OTG) in upper-middle AGC has clinical significance. However, high-level evidence-based medicine reports on the technical feasibility and oncology efficacy of LTG in the treatment of AGC are rare. Meanwhile, the tumor site, tumor characteristics, surgical difficulty and LN dissection scope of patients in the LTG group are different from those in the LDG group, so it is difficult to directly compare the oncology efficacy of these two surgical methods through survival analysis. At the same time, due to the technological difficulty and possible complications of LTG, it is less popular than LDG in clinical practice. Therefore, a long time frame is required to carry out a multicenter prospective study with a sufficient number of cases to compare the long-term outcome of LTG with ODG in AGC. In view of the DGCT study, the $\mathrm{LN}$ noncompliance rate was a surrogate indicator for the long-term survival of patients with GC $[17,18]$. CRITICS, COACT1001 and other clinical trials also use the LN noncompliance rate as a quality control indicator for D2 radical surgery in GC, and the evaluation of the $\mathrm{LN}$ noncompliance rate does not rely on the scope of gastrectomy, such as total gastrectomy or distal gastrectomy [15, $19,20]$. Therefore, this study takes the $\mathrm{LN}$ noncompliance rate as a quality control indicator to compare the oncology efficacies of LDG and LTG. Therefore, this study aims to explore the indications of LTG for the treatment of upper and middle AGC through a large-volume retrospective study of the LN noncompliance rate, which can provide a reference for future prospective randomized controlled trials.

\section{Materials and methods}

\section{General information}

A retrospective analysis was performed using the clinical and pathological data of 2401 patients who underwent GC surgery from the same group of surgeons in the Department of Gastroenterology, Union Hospital of Fujian Medical University, from June 2007 to December 2013. The inclusion criteria were as follows: (1) preoperative endoscopic biopsy confirmed gastric cancer; (2) preoperative examination confirmed no distant metastasis; and (3) intraoperative D2 radical surgery. The exclusion criteria were as follows: (1) distant metastasis; (2) exploration or palliative surgery; (3) preoperative radiotherapy and chemotherapy; (4) residual gastric cancer; (5) intraoperative combined organ resection; (6) postoperative pathology confirmed as nongastric adenocarcinoma; and (7) missing follow-up information. Finally, 1313 patients who underwent laparoscopic radical gastrectomy with preoperative clinical stage cT2-4aN0-3M0 were included in the study. All patients were informed in detail and signed informed consent before surgery. The retrospective study was approved by the ethics committee of Union Hospital of Fujian Medical University. Preoperative imaging studies were routinely performed following endoscopic and upper gastrointestinal examinations with contrast to confirm the tumor location and included computed tomography (CT) scanning, endoscopic ultrasound (EUS), and positron emission tomography-computed tomography (PETCT) as needed to evaluate the clinical stage. Based on the criteria of obesity released by 2004 World Health Organization (WHO), that is, $<25 \mathrm{~kg} / \mathrm{m}^{2}$ (normal), $25-29.9 \mathrm{~kg} / \mathrm{m}^{2}$ (pre-obesity), $30-34.9 \mathrm{~kg} / \mathrm{m}^{2}$ (obesity class I), $\geq 35 \mathrm{~kg} / \mathrm{m}^{2}$ (obesity class II), patients were classified into two groups according to their body mass index (BMI). Patients with BMI $<25 \mathrm{~kg} / \mathrm{m}^{2}$ were designated as the low-BMI group, while patients with $B M I \geq 25 \mathrm{~kg} / \mathrm{m}^{2}$ were designated as the high-BMI group in this study.

\section{Postoperative pathology examination}

After resecting the specimens, surgeons positioned each LN station according to the location of the blood vessel clips retained in the specimens during the operation and sorted each LN station according to the Japanese Research Society for Gastric Carcinoma (JRSGC) criteria. The specimens were immediately sent to the department of pathology after repacking, and the lymph nodes of each station were examined by two or more experienced pathologists through 
palpation and microscopy. In each LN station defined by the JRSGC, if more than one LN station is not detected, it is determined as LN noncompliance, which was subdivided into the $\mathrm{LN}$ compliance group (all LN stations were detected), the minor LN noncompliance group (1-2 LN stations were not detected), and the major LN noncompliance group (more than $2 \mathrm{LN}$ stations were not detected) [17, 19-22].

\section{Follow-up}

Postoperative follow-up was performed in the outpatient department every 3 months for the first 2 years, every 6 months during years 3-5, and once a year after year 5 . Most routine patient follow-up appointments included a physical examination, laboratory tests (including assessment of CA19-9, CA72-4, and CEA levels), chest radiography, abdominopelvic US or CT, and an annual endoscopic examination. The OS was calculated from the day of surgery until death or until the final follow-up date, whichever occurred first.

\section{Statistical analysis}

All statistical analyses were performed using SPSS v. 25.0 for Windows (SPSS Inc., Chicago, IL, USA). All continuous variables are presented as the mean \pm standard deviation. Chi-square or Fisher's exact tests were used to analyze categorical variables. Cumulative survival rates were compared using the Kaplan-Meier method and log-rank test. Regression analysis was performed using the Cox proportional hazards regression model in multivariate analyses. Logistic regression analysis was used to analyze risk factors. Values of $p<0.05$ were considered statistically significant.

\section{Results}

\section{Patient characteristics}

Table 1 lists the clinicopathological values of 1313 patients with GC (503 LDG vs. 810 LTG). There were 981 men and 332 women, aged from 12 to 87 years $(61.67 \pm 11.1$ years $)$. According to the UICC/AJCC 8th gastric cancer staging, there were 194 patients (14.78\%) in the cT2 stage, 392 patients $(29.86 \%)$ in the cT3 stage, and 727 patients $(55.36 \%)$ in the cT4 stage. BMI, ASA scores, PAS, histologic type, and postoperative complications were not significantly different between the LTG group and the LDG group, but in the LTG group, there were more patients who were elderly and male patients with larger tumor diameters and later tumor stages $(p<0.05)$. The average operation time of the LTG group was $192.51 \pm 54.55 \mathrm{~min}$, and the blood loss was approximately $79.54 \pm 117.46 \mathrm{ml}$. The total number of lymph nodes retrieved in the LTG group and the LDG group was $34.62 \pm 13.62$ and $32.29 \pm 11.48$, respectively, and the difference was statistically significant $(p<0.001)$.

\section{Extent of LN noncompliance}

In all patients, the LN compliance rates of the LDG group and the LTG group were $49.10 \%$ and $40.20 \%$, respectively, and the minor LN noncompliance rates were $39.20 \%$ and $39.70 \%$, respectively. The major $\mathrm{LN}$ noncompliance rates were $11.70 \%$ and $20.10 \%$, respectively. The difference was statistically significant $(p<0.001)$ (Table 2$)$. Figure 1 shows that the major LN noncompliance rates in the LDG group ranged from 9.60 to $13.40 \%$ from 2007 to 2013, while the major LN noncompliance rates in the LTG group decreased year by year from the year of operation, from $29.80 \%$ in 2007 to $12.10 \%$ in 2013 . The difference in the LN noncompliance rates between the LTG group and the LDG group was mainly caused by the LN noncompliance of the \#4, \#5, \#6, and \#12a LN stations (Supplementary Table 2).

\section{Survival analysis}

The Kaplan-Meier survival curve showed (Fig. 2) that there were statistically significant differences in OS among patients with $\mathrm{LN}$ compliance, minor $\mathrm{LN}$ noncompliance and major LN noncompliance in the whole group $(p<0.001)$. In particular, the OS of patients with major LN noncompliance was the worst, and this trend still existed in the LDG group and LTG group. Multivariate COX regression analysis of the LDG group showed that age, $\mathrm{pN}$ and LN noncompliance were independent prognostic factors for OS $(p<0.05)$. Multivariate COX regression analysis of the LTG group showed that age, tumor diameter, pT, pN, and LN noncompliance were independent prognostic factors for OS $(p<0.05)$ (Table 3).

\section{Preoperative high-risk factors for major $L N$ noncompliance in the LTG group}

Table 4 lists the preoperative risk factors of major LN noncompliance in the LTG group by univariate and multivariate logistic analysis. Multivariate analysis showed that $\mathrm{BMI} \geq 25 \mathrm{~kg} / \mathrm{m}^{2}$ and PAS were independent risk factors for major LN noncompliance in the LTG group $(p<0.05)$. Therefore, we defined patients with BMI $\geq 25 \mathrm{~kg} / \mathrm{m}^{2}$ or PAS as the LN noncompliance high-risk group and defined the remaining patients as the LN noncompliance nonhigh-risk group. In the LTG group, there was a statistically significant difference in the extent of LN noncompliance between the high-risk group and the nonhigh-risk group $(p=0.003)$. However, in the LDG group, there was no significant 
Table 1 Clinicopathological characteristics

\begin{tabular}{|c|c|c|c|}
\hline Variables & LDG $(n=503)$ & LTG $(n=810)$ & $p$ \\
\hline Age (year) & $60.03 \pm 11.58$ & $62.68 \pm 11.36$ & $<0.001$ \\
\hline $\operatorname{Sex}[n(\%)]$ & & & 0.031 \\
\hline Female & $144(28.6 \%)$ & $188(23.2 \%)$ & \\
\hline Male & $359(71.4 \%)$ & $622(76.8 \%)$ & \\
\hline Smoking $[n(\%)]$ & & & 0.525 \\
\hline No & $359(71.4 \%)$ & $592(73.1 \%)$ & \\
\hline Yes & $144(28.6 \%)$ & $218(26.9 \%)$ & \\
\hline BMI $\left(\mathrm{kg} / \mathrm{m}^{2}\right)$ & $22.17 \pm 3.2$ & $21.91 \pm 2.98$ & 0.139 \\
\hline Previous abdominal surgery $[n(\%)]$ & & & 0.52 \\
\hline No & $434(86.3 \%)$ & $688(84.9 \%)$ & \\
\hline Yes & $69(13.7 \%)$ & $122(15.1 \%)$ & \\
\hline ASA score $[n(\%)]$ & & & 0.253 \\
\hline I & $277(55.1 \%)$ & $483(59.6 \%)$ & \\
\hline II & $203(40.4 \%)$ & $291(35.9 \%)$ & \\
\hline III-IV & $23(4.6 \%)$ & $36(4.4 \%)$ & \\
\hline Size $(\mathrm{mm})$ & $44.94 \pm 19.76$ & $60.98 \pm 27.44$ & $<0.001$ \\
\hline Tumor location $[n(\%)]$ & & & $<0.001$ \\
\hline Lower & $475(94.4 \%)$ & $40(4.90 \%)$ & \\
\hline Middle & $12(2.4 \%)$ & $265(32.7 \%)$ & \\
\hline Upper & $5(1 \%)$ & $328(40.5 \%)$ & \\
\hline Overlapping lesion & $11(2.2 \%)$ & $177(21.9 \%)$ & \\
\hline Histologic type $[n(\%)]$ & & & 0.376 \\
\hline Differentiated & $190(37.8 \%)$ & $286(35.3 \%)$ & \\
\hline Undifferentiated & $313(62.2 \%)$ & $524(64.7 \%)$ & \\
\hline cT stage $[n(\%)]$ & & & $<0.001$ \\
\hline $\mathrm{cT} 2$ & $117(23.3 \%)$ & $77(9.5 \%)$ & \\
\hline cT3 & $158(31.4 \%)$ & $234(28.9 \%)$ & \\
\hline cT4 & $228(45.3 \%)$ & $499(61.6 \%)$ & \\
\hline cN stage $[n(\%)]$ & & & 0.063 \\
\hline $\mathrm{cNO}$ & $213(42.3 \%)$ & $301(37.2 \%)$ & \\
\hline $\mathrm{cN}+$ & $290(57.7 \%)$ & $509(62.8 \%)$ & \\
\hline pT stage $[n(\%)]$ & & & $<0.001$ \\
\hline $\mathrm{T} 1$ & $30(6 \%)$ & $12(1.5 \%)$ & \\
\hline $\mathrm{T} 2$ & $111(22.1 \%)$ & $78(9.6 \%)$ & \\
\hline $\mathrm{T} 3$ & $161(32 \%)$ & $281(34.7 \%)$ & \\
\hline $\mathrm{T} 4 \mathrm{a}$ & $185(36.8 \%)$ & $390(48.1 \%)$ & \\
\hline $\mathrm{T} 4 \mathrm{~b}$ & $16(3.2 \%)$ & $49(6 \%)$ & \\
\hline $\mathrm{pN}$ stage $[n(\%)]$ & & & $<0.001$ \\
\hline No & $140(27.8 \%)$ & $160(19.8 \%)$ & \\
\hline N1 & $74(14.7 \%)$ & $116(14.3 \%)$ & \\
\hline $\mathrm{N} 2$ & $115(22.9 \%)$ & $146(18 \%)$ & \\
\hline $\mathrm{N} 3 \mathrm{a}$ & $111(22.1 \%)$ & $225(27.8 \%)$ & \\
\hline $\mathrm{N} 3 \mathrm{~b}$ & $63(12.5 \%)$ & $163(20.1 \%)$ & \\
\hline Lymphovascular invasion $[n(\%)]$ & & & 0.082 \\
\hline No & $348(69.2 \%)$ & $522(64.4 \%)$ & \\
\hline Yes & $155(30.8 \%)$ & $288(35.6 \%)$ & \\
\hline Postoperative complication [ $n(\%)]$ & & & 0.381 \\
\hline None & $427(84.9 \%)$ & 688(84.9\%) & \\
\hline Grade I-II & $62(12.3 \%)$ & $89(11 \%)$ & \\
\hline Grade III-IV & $14(2.8 \%)$ & $33(4.1 \%)$ & \\
\hline Adjuvant chemotherapy $[n(\%)]$ & & & 0.855 \\
\hline
\end{tabular}


Table 1 (continued)

\begin{tabular}{lllr}
\hline Variables & LDG $(n=503)$ & LTG $(n=810)$ & \multicolumn{1}{c}{$p$} \\
\hline No & $346(68.8 \%)$ & $553(68.3 \%)$ & \\
Yes & $157(31.2 \%)$ & $257(31.7 \%)$ & 0.001 \\
LN retrieved & $32.29 \pm 11.48$ & $34.62 \pm 13.62$ & $<0.001$ \\
Operation time (min) & $173.64 \pm 55.26$ & $192.51 \pm 54.55$ & 0.286 \\
Blood loss (ml) & $72.56 \pm 100.36$ & $79.54 \pm 117.46$ & \\
\hline
\end{tabular}

Table 2 Extent of LN noncompliance

\begin{tabular}{|c|c|c|c|c|c|c|c|}
\hline \multirow[b]{2}{*}{ Compliance } & \multicolumn{2}{|c|}{ All $(n=1313)$} & \multicolumn{2}{|c|}{ LDG $(n=503)$} & \multicolumn{2}{|c|}{ LTG $(n=810)$} & \multirow{2}{*}{$\frac{p}{<0.001}$} \\
\hline & 573 & $44 \%$ & 247 & $49.10 \%$ & 326 & $40.20 \%$ & \\
\hline \multicolumn{8}{|l|}{ Noncompliance } \\
\hline Minor noncompliance $^{\mathrm{a}}$ & 518 & $39 \%$ & 197 & $39.20 \%$ & 321 & $39.70 \%$ & \\
\hline 1 & 323 & & 120 & & 203 & & \\
\hline 2 & 195 & & 77 & & 118 & & \\
\hline Major noncompliance ${ }^{a}$ & 222 & $17 \%$ & 59 & $11.70 \%$ & 163 & $20.10 \%$ & \\
\hline 3 & 103 & & 32 & & 71 & & \\
\hline 4 & 40 & & 5 & & 35 & & \\
\hline 5 & 14 & & 4 & & 10 & & \\
\hline 6 & 7 & & 1 & & 6 & & \\
\hline 7 & 20 & & 15 & & 5 & & \\
\hline 8 & 35 & & 2 & & 33 & & \\
\hline 9 & 3 & & 0 & & 3 & & \\
\hline
\end{tabular}

Data are presented as $n(\%)$

${ }^{a}$ Number of intended lymph node stations not removed

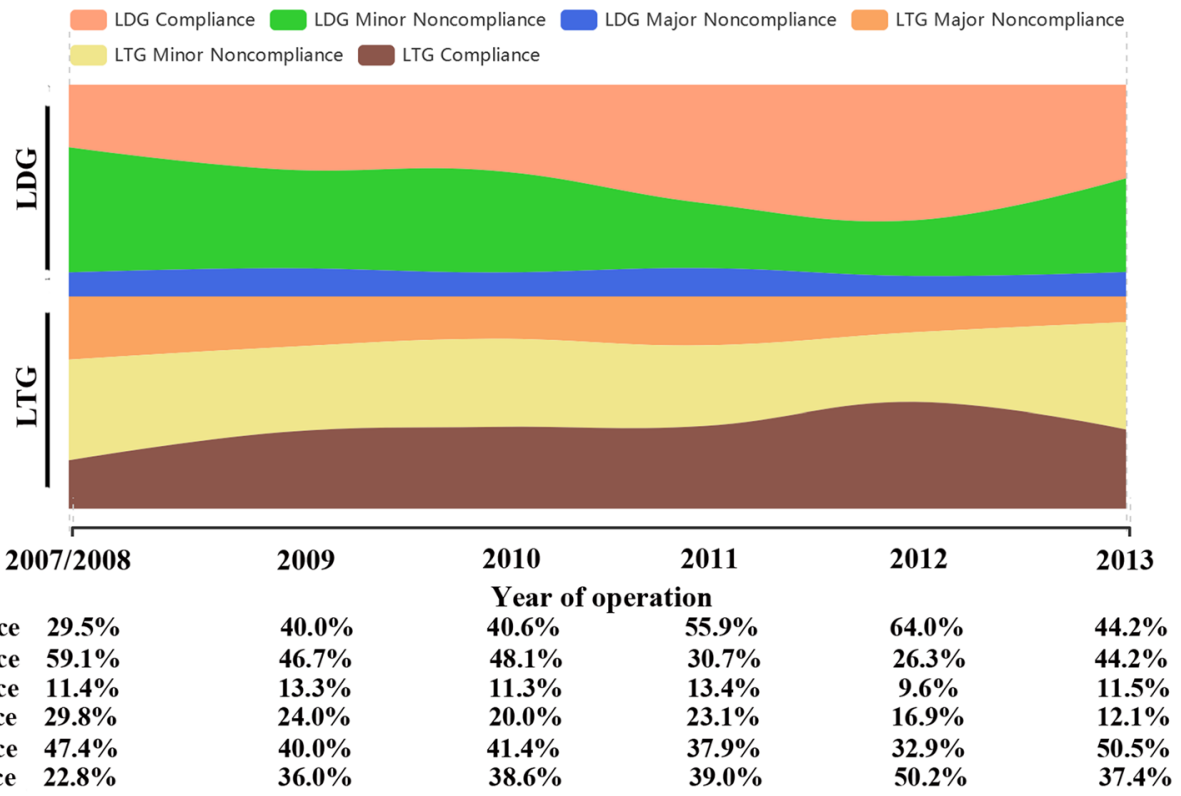

Fig. 1 Extent of LN noncompliance of LDG group and LTG group over time

difference in the extent of $\mathrm{LN}$ noncompliance between the high-risk group and the nonhigh-risk group $(p=0.456)$ (Supplementary Table 1). In addition, we retrospectively analyzed the clinicopathological data of patients who underwent open and laparoscopic radical total gastrectomy in our center from 2007 to 2013 (Supplementary Table 3). 


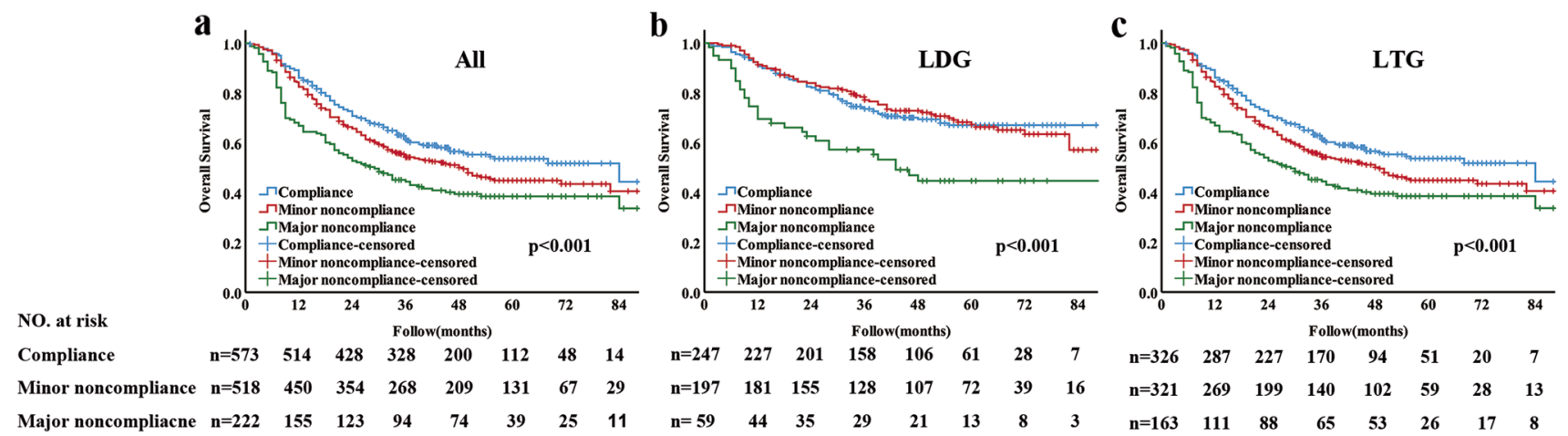

Fig. 2 Comparison of OS between compliance group, minor compliance and major compliance group in a all patients, b LDG, $\mathbf{c}$ LTG

Compared with open total gastrectomy, patients who underwent laparoscopic total gastrectomy had significantly higher rates of LN noncompliance, especially major LN noncompliance rate, in the subgroup of PAS(+) or BMI $\geq 25 \mathrm{~kg} /$ $\mathrm{m}^{2}$ (Supplementary Table 4).

\section{Middle-risk LN noncompliance patients in the LTG group}

In the nonhigh-risk group of LN noncompliance $(n=964)$, the difference in the extent of LN noncompliance between the LTG group and LDG group was still statistically significant ( $p=0.008)$ (Supplementary Table 5), which was only caused by LN noncompliance at stations \#5 and \#6 (Supplementary Table 2). When the LN dissection was completely compliant at stations \#5 and \#6, there was no difference in the extent of LN noncompliance between the LTG group and LDG group $(p=0.605)$ (Supplementary Table 5). In the nonhigh-risk LN noncompliance patients of the LTG group, logistic regression analysis indicated that a tumor diameter of $>60 \mathrm{~mm}$ was the preoperative risk factor for station \#5 LN noncompliance, and no preoperative risk factor for station \#6 LN noncompliance was found (Supplementary Table 6). Patients with a tumor diameter $>60 \mathrm{~mm}$ were defined as the middle-risk LN noncompliance group, and the rest were defined as the low-risk group. The Kaplan-Meier survival curve showed that the overall survival rate of high/ middle-risk LN noncompliance patients was significantly lower than that of the low-risk group $(p<0.001)$ (Fig. 3).

\section{Discussion}

Except for Japan and South Korea, more than $80 \%$ of GC patients in most countries worldwide are diagnosed with AGC. In the past few decades, the incidence of upper-middle GC has increased around the world [16]. Laparoscopic gastrectomy as a minimally invasive surgery is becoming increasingly popular due to advances in surgical techniques. With the accumulation of experience in laparoscopic gastrectomy for EGC, some GC treatment centers have extended the indications for laparoscopic gastrectomy from EGC to AGC. Several clinical studies have shown that surgeons can safely perform laparoscopic gastrectomy for patients with AGC. Compared with traditional open surgery, patients have less postoperative pain, faster recovery, shorter hospital stays and a better quality of life [23, 24]. Unfortunately, most of the multicenter randomized controlled clinical trials of laparoscopic gastrectomy are limited to the results of LDG, and few reports have suggested the technical feasibility and oncologic efficacy of LTG in the treatment of AGC. A large retrospective study of the oncologic efficacy of LTG in the treatment of AGC will be beneficial prior to the release of large multicenter randomized controlled clinical trials.

The Intergroup 0116 trial and other large randomized controlled clinical trials have confirmed that high-quality radical resection is the only way to cure GC, emphasizing the importance of high-quality D2 lymph node dissection [25, 26]. At the same time, DGCT, CRITICS, COACT1001 and other large multicenter randomized controlled clinical trials all used LN noncompliance as a quality control indicator for the oncologic efficacy of D2 radical surgery. Bunt AMG and Sasako M conducted a clinical study comparing the extent of LN dissection, in which, for the first time, LN noncompliance was used as an indicator of surgical quality control [22]. In this study, the LN noncompliance rate of the LTG group was significantly higher than that of the LDG group (specifically, the major LN noncompliance rate of the former was as high as $20.1 \%$ ), but the major LN noncompliance rate decreased over time. This also confirmed that the oncology efficacy of LTG, a complex surgery, was still worth affirming with the accumulation of surgical experience. Our previous studies have confirmed that LN noncompliance is an independent risk factor for poor prognosis in AGC patients undergoing LTG $[27,28]$. This study further confirmed that the OS of patients with minor LN noncompliance and major LN 
Table 3 Univariate and multivariate survival analysis of patients by Cox proportional hazards model

\begin{tabular}{|c|c|c|c|c|c|c|c|c|c|c|}
\hline \multirow[t]{3}{*}{ Variables } & \multicolumn{5}{|c|}{ LDG $(n=503)$} & \multicolumn{5}{|c|}{ LTG $(n=810)$} \\
\hline & \multirow{2}{*}{$\begin{array}{l}\text { Univariate } \\
p\end{array}$} & \multicolumn{4}{|c|}{ Multivariate model } & \multirow{2}{*}{$\begin{array}{l}\text { Univariate } \\
p\end{array}$} & \multicolumn{4}{|c|}{ Multivariate model } \\
\hline & & HR & $95 \% \mathrm{CI}$ & & $p$ & & HR & $95 \% \mathrm{C}$ & & $p$ \\
\hline Age (years) & 0.004 & & & & 0.016 & 0.006 & & & & $<0.001$ \\
\hline$<65$ & Ref & Ref & & & & Ref & Ref & & & \\
\hline$\geq 65$ & 0.004 & 1.5 & 1.078 & 2.085 & 0.016 & 0.006 & 1.651 & 1.346 & 2.025 & $<0.001$ \\
\hline Sex & 0.591 & & & & & 0.288 & & & & \\
\hline Female & Ref & & & & & Ref & & & & \\
\hline Male & 0.591 & & & & & 0.288 & & & & \\
\hline Smoking & 0.191 & & & & & 0.591 & & & & \\
\hline No & Ref & & & & & Ref & & & & \\
\hline Yes & 0.191 & & & & & 0.591 & & & & \\
\hline BMI $\left(\mathrm{kg} / \mathrm{m}^{2}\right)$ & 0.385 & & & & & 0.419 & & & & \\
\hline$<25$ & Ref & & & & & Ref & & & & \\
\hline$\geq 25$ & 0.385 & & & & & 0.419 & & & & \\
\hline Previous abdominal surgery & 0.568 & & & & & 0.676 & & & & \\
\hline No & Ref & & & & & Ref & & & & \\
\hline Yes & 0.568 & & & & & 0.676 & & & & \\
\hline Charlson score & 0.099 & & & & & 0.12 & & & & \\
\hline 0 & Ref & & & & & Ref & & & & \\
\hline $1-2$ & 0.036 & & & & & 0.411 & & & & \\
\hline $3-5$ & 0.474 & & & & & 0.049 & & & & \\
\hline ASA score & 0.005 & & & & 0.465 & 0.68 & & & & \\
\hline I & Ref & Ref & & & & Ref & & & & \\
\hline II & 0.004 & 1.211 & 0.765 & 1.917 & 0.413 & 0.38 & & & & \\
\hline III-IV & 0.028 & 1.602 & 0.749 & 3.428 & 0.224 & 0.907 & & & & \\
\hline Lymphovascular invasion & 0.21 & & & & & 0.21 & & & & \\
\hline No & Ref & & & & & Ref & & & & \\
\hline Yes & 0.21 & & & & & 0.21 & & & & \\
\hline Complications & 0.559 & & & & & 0.559 & & & & \\
\hline None & Ref & & & & & Ref & & & & \\
\hline $\mathrm{I}-\mathrm{II}^{\mathrm{a}}$ & 0.293 & & & & & 0.293 & & & & \\
\hline III-IV ${ }^{\mathrm{a}}$ & 0.751 & & & & & 0.751 & & & & \\
\hline Adjuvant chemotherapy & 0.411 & & & & & 0.411 & & & & \\
\hline No & Ref & & & & & Ref & & & & \\
\hline Yes & 0.411 & & & & & 0.411 & & & & \\
\hline Tumor diameter (mm) & $<0.001$ & & & & 0.069 & $<0.001$ & & & & 0.001 \\
\hline$<30$ & Ref & Ref & & & & Ref & Ref & & & \\
\hline $30-60$ & $<0.001$ & 1.34 & 0.896 & 2.004 & 0.154 & $<0.001$ & 1.594 & 1.254 & 2.026 & $<0.001$ \\
\hline$>60$ & 0.962 & 0.408 & 0.14 & 1.19 & 0.101 & $<0.001$ & 1.418 & 1.023 & 1.966 & 0.036 \\
\hline Primary site & 0.301 & & & & & $<0.001$ & & & & 0.574 \\
\hline Lower & Ref & & & & & Ref & Ref & & & \\
\hline Upper & 0.134 & & & & & 0.663 & 1.103 & 0.691 & 1.763 & 0.681 \\
\hline Middle & 0.262 & & & & & 0.067 & 0.937 & 0.586 & 1.5 & 0.787 \\
\hline Overlapping lesion & 0.743 & & & & & 0.345 & 1.102 & 0.679 & 1.787 & 0.694 \\
\hline cT status & $<0.001$ & & & & 0.136 & $<0.001$ & & & & 0.461 \\
\hline $\mathrm{cT} 2$ & Ref & Ref & & & & Ref & Ref & & & \\
\hline cT3 & 0.025 & 1.637 & 0.697 & 3.845 & 0.258 & 0.025 & 1.316 & 0.608 & 2.849 & 0.486 \\
\hline $\mathrm{cT} 4$ & $<0.001$ & 2.123 & 0.987 & 4.565 & 0.054 & $<0.001$ & 0.994 & 0.493 & 2.002 & 0.986 \\
\hline $\mathrm{cN}$ status & $<0.001$ & & & & 0.567 & $<0.001$ & & & & 0.6 \\
\hline
\end{tabular}


Table 3 (continued)

\begin{tabular}{|c|c|c|c|c|c|c|c|c|c|c|}
\hline \multirow[t]{3}{*}{ Variables } & \multicolumn{5}{|c|}{ LDG $(n=503)$} & \multicolumn{5}{|c|}{ LTG $(n=810)$} \\
\hline & \multirow{2}{*}{$\begin{array}{l}\text { Univariate } \\
p\end{array}$} & \multicolumn{4}{|c|}{ Multivariate model } & \multirow{2}{*}{$\begin{array}{l}\text { Univariate } \\
p\end{array}$} & \multicolumn{4}{|c|}{ Multivariate model } \\
\hline & & HR & $95 \% \mathrm{Cl}$ & & $p$ & & HR & $95 \% \mathrm{C}$ & & $p$ \\
\hline $\mathrm{cNO}$ & Ref & Ref & & & & Ref & Ref & & & \\
\hline $\mathrm{cN}+$ & $<0.001$ & 1.111 & 0.774 & 1.595 & 0.567 & $<0.001$ & 1.064 & 0.844 & 1.342 & 0.6 \\
\hline pT status & $<0.001$ & & & & 0.571 & $<0.001$ & & & & 0.019 \\
\hline pT1 & Ref & Ref & & & & Ref & Ref & & & \\
\hline pT2 & 0.667 & 0.677 & 0.25 & 1.834 & 0.443 & 0.708 & 2054 & 0 & $3 E+21$ & 0.72 \\
\hline pT3 & 0.379 & 0.607 & 0.219 & 1.679 & 0.336 & 0.686 & 1782 & 0 & $2 \mathrm{E}+21$ & 0.725 \\
\hline pT4a & 0.005 & 0.824 & 0.298 & 2.281 & 0.709 & 0.663 & 3150 & 0 & $4 \mathrm{E}+21$ & 0.705 \\
\hline $\mathrm{pT} 4 \mathrm{~b}$ & 0.017 & 1.195 & 0.343 & 4.163 & 0.78 & 0.645 & 4419 & 0 & $5 E+21$ & 0.693 \\
\hline $\mathrm{pN}$ status & $<0.001$ & & & & $<0.001$ & $<0.001$ & & & & $<0.001$ \\
\hline pNO & Ref & Ref & & & & Ref & Ref & & & \\
\hline $\mathrm{pN} 1$ & 0.15 & 1.565 & 0.78 & 3.139 & 0.208 & 0.203 & 1.122 & 0.689 & 1.828 & 0.644 \\
\hline $\mathrm{pN} 2$ & 0.005 & 1.914 & 1.016 & 3.606 & 0.045 & $<0.001$ & 1.804 & 1.162 & 2.802 & 0.009 \\
\hline $\mathrm{pN} 3 \mathrm{a}$ & $<0.001$ & 3.893 & 2.114 & 7.169 & $<0.001$ & $<0.001$ & 3.189 & 2.111 & 4.816 & $<0.001$ \\
\hline $\mathrm{pN} 3 \mathrm{~b}$ & $<0.001$ & 7.291 & 3.797 & 13.998 & $<0.001$ & $<0.001$ & 4.372 & 2.809 & 6.804 & $<0.001$ \\
\hline Grade & 0.018 & & & & 0.827 & 0.018 & & & & 0.718 \\
\hline Differentiated & Ref & Ref & & & & Ref & Ref & & & \\
\hline Undifferentiated & 0.018 & 1.04 & 0.733 & 1.474 & 0.827 & 0.018 & 0.958 & 0.76 & 1.208 & 0.718 \\
\hline LN noncompliance & 0.001 & & & & $<0.001$ & $<0.001$ & & & & $<0.001$ \\
\hline Compliance & Ref & Ref & & & & Ref & Ref & & & \\
\hline Minor noncompliance & 0.933 & 1.166 & 0.818 & 1.664 & 0.396 & 0.051 & 1.433 & 1.135 & 1.809 & 0.003 \\
\hline Major noncompliance & $<0.001$ & 2.768 & 1.779 & 4.307 & $<0.001$ & $<0.001$ & 2.524 & 1.921 & 3.314 & $<0.001$ \\
\hline
\end{tabular}

noncompliance was significantly worse than that of patients without LN noncompliance, especially the patients with major LN noncompliance had the worst OS. Therefore, for patients planning to undergo LTG surgery, identifying highrisk groups with major $\mathrm{LN}$ noncompliance before surgery is of great importance. Logistic regression analysis showed that the independent risk factors for major $\mathrm{LN}$ noncompliance in the LTG group were BMI $\geq 25 \mathrm{~kg} / \mathrm{m}^{2}$ and PAS $(p<0.05)$. In recent years, a number of studies have reported that high BMI or increased intra-abdominal fat would lead directly to a reduced number of LNs detected [29-33]. High BMI patients often have massive adipose tissue accumulation in the abdomen, and it is often difficult to distinguish the relationship between pancreatic tissue, fat tissue and LNs during surgery, which makes lymph node dissection more difficult. Moreover, in the process of dissection, there is more exudation of tissue and blood, which affects the exposure of LNs and the resection plane under laparoscopy for the surgeon and assistant. With the popularity of laparoscopic surgery, many patients who have undergone abdominal surgery are also candidates for laparoscopic gastrectomy. A number of retrospective studies have found no difference in the shortterm efficacy of laparoscopic-assisted gastrectomy in PAS and non-PAS patients [34-38]. In these studies, however, the included population was limited to a history of upper abdominal surgery. Yamashita first studied the feasibility of LG in all types of abdominal surgery, and the results showed that the rate of conversion to open laparotomy was higher in patients with a previous history of lower gastrointestinal surgery or patients requiring total gastrectomy than in the control group [39]. Since LTG surgery requires a wider scope of lymph node dissection, the adhesion of the previous surgical area undoubtedly increases the difficulty of lymph node dissection and the incidence of $\mathrm{LN}$ noncompliance.

In this study, we chose patients for LDG as a reference to assess the surgical results of LTG in the same surgical period because a number of large clinical trials have confirmed the curative effect and technical feasibility of LDG for AGC, and many surgeons have a wealth of experience with LDG, which may provide a theoretical basis for LTG for the treatment of AGC. The LN noncompliance rate, a relatively comparable surgical quality control indicator, was used as the evaluation criterion, and LDG was taken as a reference to analyze the surgical indications of LTG, which is helpful for guiding gastric cancer surgeons in mastering strictly therapeutic indications of LTG for the treatment of advanced upper and middle gastric cancer and ultimately benefiting the survival of patients. Except for the high-risk group with major LN noncompliance, the LN noncompliance rate of the LTG group was still higher than that of the LDG group 
Table 4 Univariate and multivariate logistic regression analysis of risk factors for major noncompliance after LTG

\begin{tabular}{|c|c|c|c|c|c|c|c|c|}
\hline \multirow{3}{*}{$\begin{array}{l}\text { Variables } \\
\text { Age (year) }\end{array}$} & \multicolumn{4}{|c|}{ Univariate model } & \multicolumn{4}{|c|}{ Multivariate model } \\
\hline & \multirow[t]{2}{*}{ OR } & \multicolumn{2}{|l|}{$95 \% \mathrm{CI}$} & \multirow{2}{*}{$\frac{p}{0.413}$} & \multirow[t]{2}{*}{ OR } & \multicolumn{2}{|l|}{$95 \%$ CI } & \multirow[t]{2}{*}{$p$} \\
\hline & & & & & & & & \\
\hline$<65$ & Ref & & & & & & & \\
\hline$\geq 65$ & 0.865 & 0.61 & 1.225 & 0.413 & & & & \\
\hline Sex & & & & 0.704 & & & & \\
\hline Female & Ref & & & & & & & \\
\hline Male & 1.083 & 0.717 & 1.636 & 0.704 & & & & \\
\hline Smoking & & & & 0.336 & & & & \\
\hline No & Ref & & & & & & & \\
\hline Yes & 0.822 & 0.552 & 1.225 & 0.336 & & & & \\
\hline BMI $\left(\mathrm{kg} / \mathrm{m}^{2}\right)$ & & & & 0.048 & & & & 0.049 \\
\hline$<25$ & Ref & & & & Ref & & & \\
\hline$\geq 25$ & 1.602 & 1.005 & 2.555 & 0.048 & 1.589 & 1.0055 & 2.538 & 0.049 \\
\hline Previous abdominal surgery & & & & 0.04 & & & & 0.044 \\
\hline No & Ref & & & & Ref & & & \\
\hline Yes & 1.592 & 1.022 & 2.478 & 0.04 & 1.58 & 1.013 & 2.463 & 0.044 \\
\hline ASA score & & & & 0.343 & & & & \\
\hline I & Ref & & & & & & & \\
\hline II & 1.299 & 0.908 & 1.858 & 0.153 & & & & \\
\hline III-IV & 1.265 & 0.558 & 2.868 & 0.574 & & & & \\
\hline Charlson score & & & & 0.076 & & & & \\
\hline 0 & Ref & & & & & & & \\
\hline $1-2$ & 1.423 & 0.989 & 2.049 & 0.058 & & & & \\
\hline $3-5$ & 2.268 & 0.758 & 6.781 & 0.143 & & & & \\
\hline cT status & & & & 0.203 & & & & \\
\hline $\mathrm{cT} 2$ & Ref & & & & & & & \\
\hline cT3 & 0.706 & 0.391 & 1.277 & 0.25 & & & & \\
\hline cT4 & 0.611 & 0.352 & 1.059 & 0.079 & & & & \\
\hline $\mathrm{cN}$ status & & & & 0.422 & & & & \\
\hline cNO & Ref & & & & & & & \\
\hline $\mathrm{cN}$ & 0.866 & 0.609 & 1.231 & 0.422 & & & & \\
\hline Tumor diameter (mm) & & & & 0.078 & & & & \\
\hline$<30$ & Ref & & & & & & & \\
\hline $30-60$ & 0.627 & 0.417 & 0.944 & 0.025 & & & & \\
\hline$>60$ & 0.953 & 0.567 & 1.604 & 0.857 & & & & \\
\hline Grade & & & & 0.64 & & & & \\
\hline Differentiated & Ref & & & & & & & \\
\hline Undifferentiated & 1.09 & 0.759 & 1.567 & 0.64 & & & & \\
\hline
\end{tabular}

$(p<0.001)$. Further analysis of the $\mathrm{LN}$ noncompliance rate of each LN station in LDG and LTG showed that the LN noncompliance rate of stations \#5 and \#6 in the LTG group was significantly higher than that in the LDG group. If LN dissections for stations \#5 and \#6 were completely compliant, the difference in the LN noncompliance rate between the LTG group and LDG group disappeared, which further confirmed that the high LN noncompliance rate in the LTG group originated from stations \#5 and \#6 LN noncompliance. Compared with the LDG group, patients in the LTG group had larger tumor diameters, later tumor stages and other adverse factors, which affected lymph node dissection, especially in the lymph node dissection of the superior and inferior regions of the pylorus. Logistic regression analysis showed that a tumor diameter of $>60 \mathrm{~mm}$ was a preoperative risk factor for \#5 LN noncompliance. We believe that in the process of laparoscopic radical gastrectomy to dissect \#5 LN, a larger tumor in the middle and upper part of the stomach may lead to more limited space in the narrow superior pyloric region, affecting the exposure of lymphatic adipose tissue around the right gastric vascular region and surrounding areas for the surgeon and his or her assistants, 


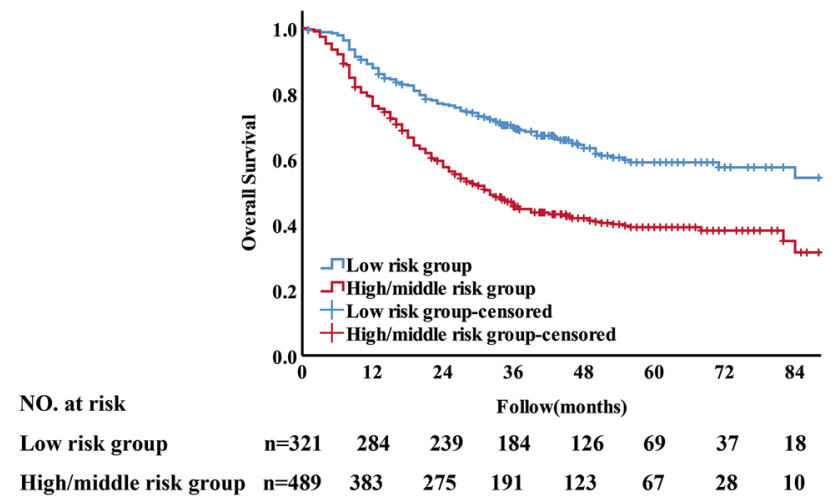

Fig. 3 Comparison of OS between LN noncompliance low-risk group and high/middle group

which may lead to the omission of lymph node dissection in this surgical field. Therefore, patients with a tumor diameter $>60 \mathrm{~mm}$ in the advanced stage of upper-middle gastric cancer represent the middle-risk group with $\mathrm{LN}$ noncompliance in LTG surgery, which should be carefully selected. However, similar to other retrospective studies, our research also has the following limitations. First, this is a singlecenter retrospective study, some potential biases cannot be avoided, and multicenter prospective studies are still needed. Second, with the technological innovation of laparoscopic instruments and the accumulation of laparoscopic operation experience, our center has performed laparoscopic surgery on more and more gastric cancer patients, far more than those who underwent open surgery [28, 40-42]. Therefore, it is difficult to conduct a retrospective comparison study on the LN noncompliance rate between open and laparoscopic total gastrectomy for large number of cases in the same period. We compared the LN noncompliance data of patients who underwent open and laparoscopic radical total gastrectomy in our center from 2007 to 2013. Due to the limited number of patients with open GC surgery, deeper stratification analysis is not possible, we expect to further explore the indications of LTG by directly comparing the rate of $\mathrm{LN}$ noncompliance between the OTG group and the LTG group in the future through the high-volume multicenter perspective clinical trials in the same period.

In conclusion, LN noncompliance is an independent prognostic factor for poor prognosis in patients after LTG. Based on this finding, patients with a BMI $\geq 25 \mathrm{~kg} / \mathrm{m}^{2}$, history of previous abdominal surgery and tumor diameter $>60 \mathrm{~mm}$ in the advanced stage of upper-middle gastric cancer represent high/middle-risk groups with LN noncompliance in LTG surgery, which should be carefully selected.

Author contributions QYC, GTL, CMH conceived the study, analyzed the data, and drafted the manuscript, $\mathrm{CHZ}$ and QZ helped critically revise the manuscript for important intellectual content. PL, JWX, JBW, JXL, JL and LLC helped collect data and design the study.

Funding This work was supported by Scientific and technological innovation joint capital projects of Fujian Province, China (no. 2016Y9031). Minimally invasive medical center of Fujian Province (no. [2017]171). National key clinical specialty discipline construction program of China (no. [2012]649).

\section{Compliance with ethical standards}

Conflict of interest The authors declare that they have no conflict of interest.

Human rights All procedures followed were in accordance with the ethical standards of the responsible committee on human experimentation (institutional and national) and with the Helsinki Declaration of 1964 and later versions.

Informed consent Informed consent or substitute for it was obtained from all patients for being included in the study.

\section{References}

1. Torre LA, Bray F, Siegel RL, et al. Global cancer statistics, 2012. CA Cancer J Clin. 2015;65(2):87-108.

2. Orditura M, Galizia G, Sforza V, et al. Treatment of gastric cancer. World J Gastroenterol. 2014;355(7):729-35.

3. Cuschieri A, Weeden S, Fielding J, et al. Patient survival after D1 and $\mathrm{D} 2$ resections for gastric cancer: long-term results of the MRC randomized surgical trial. Br J Cancer. 1999;79(9-10):1522-30.

4. Feinstein AR, Sosin DM, Wells CK. The Will Rogers phenomenon. Stage migration and new diagnostic techniques as a source of misleading statistics for survival in cancer. N Engl J Med. 1985;312(25):1604-8.

5. Songun I, Putter H, Kranenbarg EM, et al. Surgical treatment of gastric cancer: 15-year follow-up results of the randomised nationwide Dutch D1D2 trial. Lancet Oncol. 2010;11(5):439-49.

6. Kitano S, Iso Y, Moriyama M, et al. Laparoscopy-assisted Billroth I gastrectomy. Surg Laparosc Endosc. 1994;4(2):146-8.

7. Han HS, Kim YW, Yi NJ, et al. Laparoscopy-assisted D2 subtotal gastrectomy in early gastric cancer. Surg Laparosc Endosc Percutan Tech. 2003;13(6):361-5.

8. Lee JH, Han HS, Lee JH. A prospective randomized study comparing open vs laparoscopy-assisted distal gastrectomy in early gastric cancer: early results. Surg Endosc. 2005;19(2):168-73.

9. Lee JH, Yom CK, Han HS. Comparison of long-term outcomes of laparoscopy-assisted and open distal gastrectomy for early gastric cancer. Surg Endosc. 2009;23(8):1759-63.

10. Smyth EC, Verheij M, Allum W, et al. Gastric cancer: ESMO Clinical Practice Guidelines for diagnosis, treatment and followup. Ann Oncol. 2016;27(suppl 5):v38-v49.

11. Tanimura S, Higashino M, Fukunaga Y, et al. Laparoscopic gastrectomy for gastric cancer: experience with more than 600 cases. Surg Endosc. 2008;22(5):1161-4.

12. Kawamura H, Homma S, Yokota R, et al. Inspection of safety and accuracy of D2 lymph node dissection in laparoscopy-assisted distal gastrectomy. World J Surg. 2008;32(11):2366-70.

13. Hu Y, Huang C, Sun Y, et al. Morbidity and mortality of laparoscopic versus open D2 distal gastrectomy for advanced gastric cancer: a randomized controlled trial. J Clin Oncol. 2016;34(12):1350-7. 
14. Yu J, Huang C, Sun Y, et al. Effect of laparoscopic vs open distal gastrectomy on 3-year disease-free survival in patients with locally advanced gastric cancer: the CLASS-01 randomized clinical trial. JAMA. 2019;321(20):1983-92.

15. Park YK, Yoon HM, Kim YW, et al. Laparoscopy-assisted versus open D2 distal gastrectomy for advanced gastric cancer: results from a randomized phase II multicenter clinical trial (COACT 1001). Ann Surg. 2018;267(4):638-45.

16. Kubo A, Corley DA. Marked regional variation in adenocarcinomas of the esophagus and the gastric cardia in the United States. Cancer. 2002;95(10):2096-102.

17. Bonenkamp JJ, Hermans J, Sasako M, et al. Quality control of lymph node dissection in the Dutch randomized trial of D1 and D2 lymph node dissection for gastric cancer. Gastric Cancer. 1998;1(2):152-9.

18. de Steur WO, Hartgrink HH, Dikken JL, et al. Quality control of lymph node dissection in the Dutch Gastric Cancer Trial. Br J Surg. 2015;102(11):1388-93.

19. Claassen YHM, de Steur WO, Hartgrink HH, et al. Surgicopathological quality control and protocol adherence to lymphadenectomy in the CRITICS gastric cancer trial. Ann Surg. 2018;268(6):1008-133.

20. Claassen YHM, van Sandick JW, Hartgrink HH, et al. Association between hospital volume and quality of gastric cancer surgery in the CRITICS trial. Br J Surg. 2018;105(6):728-35.

21. Sano T, Aiko T. New Japanese classifications and treatment guidelines for gastric cancer: revision concepts and major revised points. Gastric Cancer. 2011;14(2):97-100.

22. Bunt AM, Hermans J, Boon MC, et al. Evaluation of the extent of lymphadenectomy in a randomized trial of Western- versus Japanese-type surgery in gastric cancer. J Clin Oncol. 1994;12(2):417-22.

23. Lin JX, Huang CM, Zheng CH, et al. Laparoscopy-assisted gastrectomy with D2 lymph node dissection for advanced gastric cancer without serosa invasion: a matched cohort study from South China. World J Surg Oncol. 2013;11(1):1-9.

24. Nam BH, Kim YW, Reim D, et al. Laparoscopy assisted versus open distal gastrectomy with D2 lymph node dissection for advanced gastric cancer: design and rationale of a phase II randomized controlled multicenter trial (COACT 1001). J Gastr Cancer. 2013;13(3):164-71.

25. Lee J, Lim DH, Kim S, et al. Phase III trial comparing capecitabine plus cisplatin versus capecitabine plus cisplatin with concurrent capecitabine radiotherapy in completely resected gastric cancer with D2 lymph node dissection: the ARTIST trial. J Clin Oncol. 2012;30(3):268-73.

26. Macdonald JS, Smalley SR, Benedetti J, et al. Chemoradiotherapy after surgery compared with surgery alone for adenocarcinoma of the stomach or gastroesophageal junction. N Engl J Med. 2001;345(10):725-30.

27. Lin GT, Chen QY, Zheng CH, et al. Lymph node noncompliance affects the long-term prognosis of patients with gastric cancer after laparoscopic total gastrectomy. J Gastrointest Surg. 2019;1:1.
28. Chen QY, Zhong Q, Liu ZY, et al. Does noncompliance in lymph node dissection affect oncological efficacy in gastric cancer patients undergoing radical gastrectomy? Ann Surg Oncol. 2019;26(6):1759-71.

29. Kim MG, Kim KC, Kim BS, et al. A totally laparoscopic distal gastrectomy can be an effective way of performing laparoscopic gastrectomy in obese patients (body mass index $\geq 30$ ). World $\mathrm{J}$ Surg. 2011;35(6):1327-32.

30. Miyaki A, Imamura K, Kobayashi R, et al. Impact of visceral fat on laparoscopy-assisted distal gastrectomy. Surgeon. 2013;11(2):76-81.

31. Sugimoto M, Kinoshita T, Shibasaki H, et al. Short-term outcome of total laparoscopic distal gastrectomy for overweight and obese patients with gastric cancer. Surg Endosc. 2013;27(11):4291-6.

32. Lee HJ, Kim HH, Kim MC, et al. The impact of a high body mass index on laparoscopy assisted gastrectomy for gastric cancer. Surg Endosc Other Intervent Tech. 2009;23(11):2473-9.

33. Ojima T, Iwahashi M, Nakamori M, et al. The impact of abdominal shape index of patients on laparoscopy-assisted distal gastrectomy for early gastric cancer. Langenbecks Arch Surg. 2012;397(3):437-45.

34. Nunobe S, Hiki N, Fukunaga T, et al. Previous laparotomy is not a contraindication to laparoscopy-assisted gastrectomy for early gastric cancer. World J Surg. 2008;32(7):1466.

35. Tokunaga M, Hiki N, Fukunaga T, et al. Laparoscopy-assisted gastrectomy for patients with earlier upper abdominal open surgery. Surg Laparosc Endosc Percutaneous Tech. 2010;20(1):16-9.

36. Nagai E, Nakata K, Ohuchida K, et al. Laparoscopic total gastrectomy for remnant gastric cancer: feasibility study. Surg Endosc. 2014;28(1):289-96.

37. Kwon IG, Cho I, Guner A, et al. Minimally invasive surgery for remnant gastric cancer: a comparison with open surgery. Surg Endosc. 2014;28(8):2452-8.

38. Tsunoda S, Okabe H, Obama K, et al. Laparoscopic gastrectomy for patients with a history of upper abdominal surgery: results of a matched-pair analysis. Surg Today. 2014;44(2):271-6.

39. Yamashita K, Miyazaki Y, Takahashi T, et al. Safety and feasibility of laparoscopic gastrectomy for gastric cancer patients with a history of abdominal surgery. Surg Today. 2017;47(10):1-8.

40. Lin JX, Huang CM, Zheng CH, et al. Laparoscopy-assisted gastrectomy with D2 lymph node dissection for advanced gastric cancer without serosa invasion: a matched cohort study from South China. World J Surg Oncol. 2013;11:4.

41. Lin JX, Huang CM, Zheng CH, et al. Evaluation of laparoscopic total gastrectomy for advanced gastric cancer: results of a comparison with laparoscopic distal gastrectomy. Surg Endosc. 2016;30(5):1988-98.

42. Chen QY, Zheng CH, Li P, et al. Safety and prognostic impact of prophylactic laparoscopic superior mesenteric vein (No. $14 \mathrm{v})$ lymph node dissection for lower-third gastric cancer: a propensity score-matched case-control study. Surg Endosc. 2018;32(3):1495-505.

\section{Affiliations}

\section{Qi-Yue Chen ${ }^{1,2,3}$. Guang-Tan Lin ${ }^{1,2}$. Qing Zhong ${ }^{1,2}$. Chao-Hui Zheng ${ }^{1,2,3} \cdot$ Ping $\mathrm{Li}^{1,2,3}$. Jian-Wei Xie ${ }^{1,2,3}$. Jia-Bin Wang ${ }^{1,2,3}$. Jian-Xian Lin ${ }^{1,2,3}$. Jun $\mathrm{Lu}^{1,2,3} \cdot$ Long-Long Cao ${ }^{1,2}$. Chang-Ming Huang ${ }^{1,2,3}$}

1 Department of Gastric Surgery, Fujian Medical University Union Hospital, No. 29 Xinquan Road, Fuzhou 350001, Fujian, China

2 Department of General Surgery, Fujian Medical University Union Hospital, Fuzhou, China
3 Key Laboratory of Ministry of Education of Gastrointestinal Cancer, Fujian Medical University, Fuzhou, China 